\title{
NANOTECHNOLOGY IN SPORT AND SECURITY
}

\author{
Adelina Miteva \\ Space Research and Technology Institute - Bulgarian Academy of Sciences (Bulgaria)
}

\begin{abstract}
Nanotechnologies are practically applicable in all important areas of industry and everyday life. Nanotechnology is an interdisciplinary field covering natural and engineering sciences (e.g. mathematics, chemistry, physics, biology, military sciences, etc.), as well as health sciences due to its versatility. This article provides a brief overview of some of the current and potential applications of nanotechnology in sport and sports security. Some examples of what is and what can be created with the help of nanotechnology in these areas are given, for example: unique characteristic sports equipment, sportswear and architecture; ultra-small computers, durable and multifunctional materials for use in clothing, shoes, etc. A critical discussion is presented. Possible future extensions of work in this area are considered.
\end{abstract}

Keywords: sport; nanotechnology; sports applications; security; nanodevices; nanomaterials

\section{Introduction}

One of the most active areas of research in modern material science is the field of nanotechnology (NT). NT can meet almost all of our needs (Booker \& Boysen 2005). Done right, it increases our standard of living - makes our lives more secure, improves healthcare delivery, and optimizes our use of limited resources (Harifi $\&$ Montazer 2017). We live in the era of Nano- and biotechnology. The number of publications in the NT area of research has been increasing exponentially in the past 20 years. This is due to the great and growing interest in numerous NT applications, mainly materials and devices, in various fields of industry, science and everyday life. NT is an interdisciplinary field of applied and fundamental science and technology that deals with a set of theoretical foundations as well as practical research, synthesis and analysis, production methods and the use of products with a given atomic structure through the controlled manipulation of individual molecules and atoms (Ćibo et. al. 2019). Figure 1 illustrates the differences in scale, which vary from the diameter of the hair to one hydrogen atom.

Corporations, universities and military / government laboratories are working together to further study nanotechnology, as there are many perspectives in many applications, and one of the most important is sport and sports security. Many nanotechnology sports products (Gong 2013) are already on the market. 


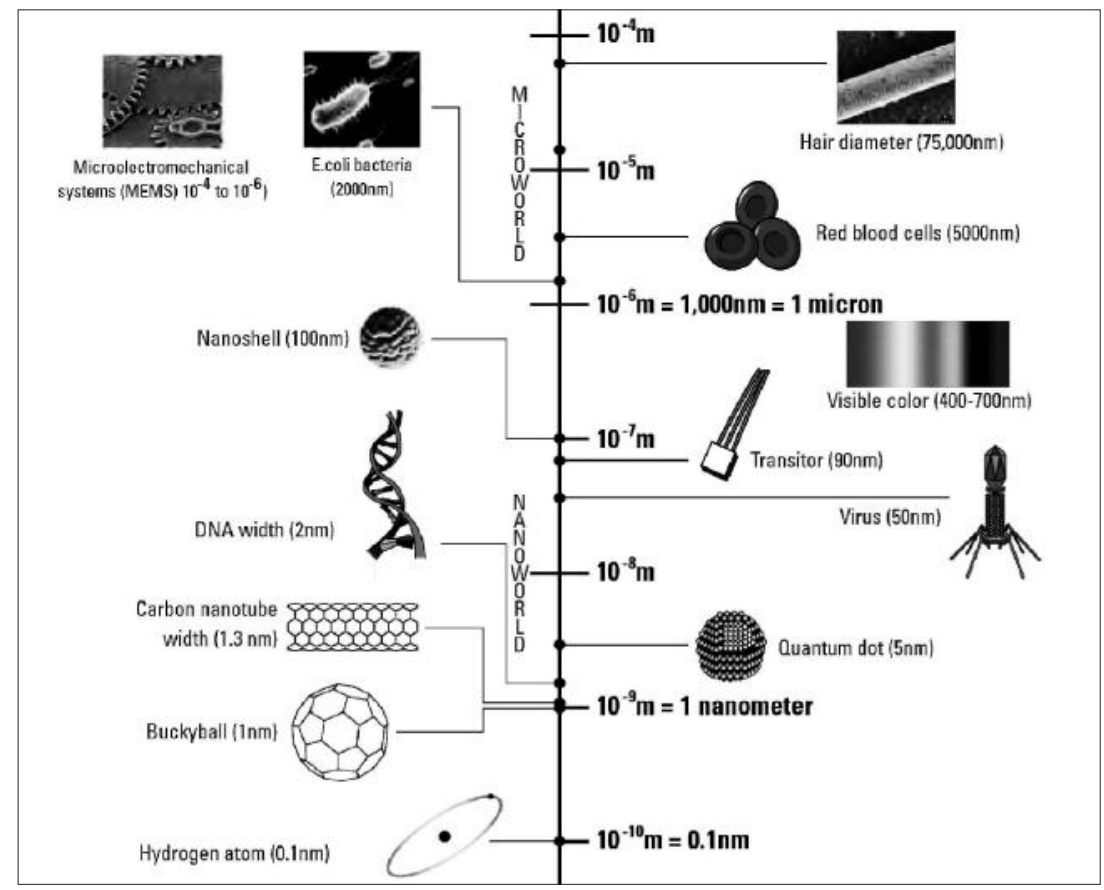

Figure 1. Size comparisons, from hair diameter $(75.000 \mathrm{~nm})$ to the hydrogen atom $(0.1 \mathrm{~nm})$

\section{Purpose}

In this study a brief overview of some of the current and potential applications of NT in sport and sports security is presented. Some examples of what is and what can be created with the help of nanotechnology in these areas are given. A critical discussion is presented. Possible future extensions of work in this area are considered.

\section{Methodology}

Some of the information presented in this study is compiled from the available literature on nanotechnology and can be considered as a brief introductory review of the above topic. Some results obtained by me and co-authors relevant to the topic of this publication, are mentioned.

When creating this article, several scientific methods were used: obtaining information on the topic through literary search, analysis, creativity, logic and synthesis of literature; experience and knowledge in the field of NT served as the basis for the creation of the proposed conclusions. 


\section{Results and Discussion}

Using nanomaterials in sport engineering resulted in scientific development of sport (Ćibo et.al. 2019). Nowadays NT has been widely used in various sports, sport venues, sport equipment and sport coatings, floor coverings and clothing (Zhao \& Shen 2012). Famous sport companies are looking for new and novel ideas for increased application of NT in their sport products attaining desired properties.

Some of the endless benefits of using NT in sport and sports security are: improvement the quality of sports equipment and sports facilities; increasing the durability of equipment and facilities; increasing sportsmen performance; a sense of comfort and safety for sportsmen; reduces the likelihood of injury and increases maneuverability compared to the equipment used earlier; more agile sportsmen than ever. And some of the NT advantages in sports equipment are: increased endurance; increased hardness; reduced weight; wear resistance; resilience; reduced friction; improved strength to weight ratio; it's safer; increases the degree of competitiveness in sports.

\section{Types of nanomaterials used in sports}

NT applications in sport include mainly used nanomaterials such as carbon nanotubes (CTN), silica $\left(\mathrm{SiO}_{2}\right)$ nanoparticles, fullerenes, carbon nanoparticles (NP), giving many properties to various sports equipment (Harifi \& Montazer 2017).

CNT, the most commonly used material in nano-enhanced sports equipment, have a higher specific strength and specific stiffness than other conventional materials. They are 100 times stronger and 6 times lighter than steel and rigid as a diamond, making them an ideal component for making sports equipment where low weight and high strength have primary importance. CNT are used to create super-strong steering wheels for mountain bikes, durable tennis rackets and ultralightweight bicycle frames (Zhao \& Shen 2012).

Silica NP is a material used to produce glass characterized as a bad heat conductor. Silica coatings make the skeleton of aerogel. Silica aerogels are made of NP of aerated airborne NP. As a result, this substance is mostly made up of air. Since both air and silica have very low thermal conductivity, they are excellent insulators. These features make nano-aerogels one of the currently the best heat insulators (Ćibo et.al. 2019). Silica NP are incorporated in such sports as: tennis/badminton (increase stability, power and durability of racquets); skiing (decrease torsion index and facilitate transition in skins); fly-fishing (enhance hoop and flex strength of rods).

Fullerene is an allotropic carbon modification which doped with potassium exhibits superconductive properties. They find application in tennis/badminton (reduce weight and twisting o racquets frames), golf (facilitate flexible club whipping), bowling (reduce chipping and cracking of balls).

Carbon nanoparticles have widely been applied in sport such as road racing. The electrical conductivity of polymer materials, like carbon nanoparticles, can be considerably improved by incorporation of conductive fillers. The latest discovery from Rice University is the result of research that lasted for more than ten years, and 
despite this, it has caused quite a shock. Rice scientists, the US Air Force and the Israeli Technion Institute discovered that they produced a new type of carbon microtubes (CNT), or microfibers that look similar to textile fibers, or carry heat and electricity such as metal wire. In a journal, scientists have described the process of industrial production that has ended and whose characteristics in many ways go beyond existing commercially available high-performance materials (Ćibo et.al. 2019).

Carbon nanotubes have been applied in tennis and badminton racquets to reduce their weight and increase their elasticity, durability and hand-feeling. These racquets are mostly made of graphite and carbon fibers. Coating tennis balls with nanoparticles such as nano-clay greatly extends the ball service life due to gas barrier effect slowing down the speed of air penetration into the ball. Bicycles with carbon nanotube frames are light-weight while having rigidity.

Today's sport venues have been dramatically changed through application of nanomaterials in the construction of sport stadiums (roof, floors, walls and glasses), field turf and racks. Nano-films with higher resistance to water and moisture are applied on flooring and walls of stadiums preventing the formation of rust and defects, maintaining their long-term cleanliness and extending their service life (Harifi \& Montazer 2017). Painting the stadium walls with nano-paints including $\mathrm{SiO}_{2}$ nanoparticles with antibacterial, self-cleaning and anti-stain properties purifies the indoor environment, insulates the heat and protects the area against ultraviolet (UV) radiation of sun.

Nanotechnology-based textiles (nanotextiles)

NT in textile industry (Montazer et. al. 2016) provides various high-quality products (see Figure 2).

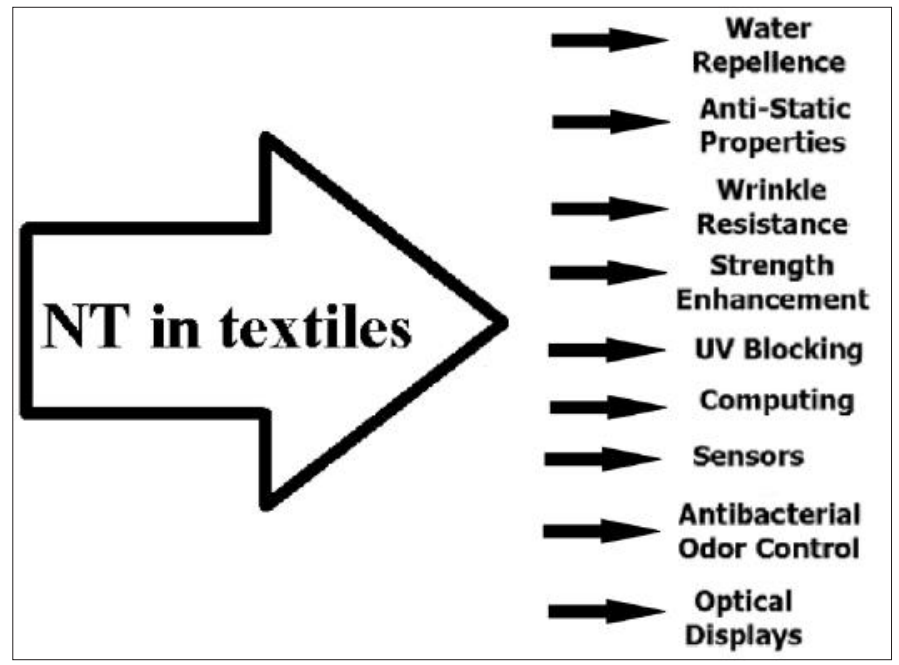

Figure 2. Applications of nanotechnology in textiles 
For textiles in sportswear and equipment, the most important thing is to protect the health and life of athletes, as well as to make them feel comfortable. Over the last two decades, numerous nanostructures and nanomaterials including NP, CNT, Bragg diffraction gratings, and nanoelectronics components have been deposited or woven into textiles. The development of these nanomaterials also creates new fabrication methods involving particle impregnation, spray coating, multifunctional composite fiber drawing, and direct weaving at an industrial scale. The application of nanomaterials in the form of surface modifications, electronics, and optics offers functionality as well as the potential of improved appearance. Realized nanotechnology applications in textiles include antibacterial properties, odor control, UV protection, water repellence, wrinkle resistance, antistatic properties, and strength enhancements (Table 1). One of the important NT applications in textile industry is devoted to stadium/gym floor coverings that affects the performance and safety of athletes and on the other hand intensifies the flooring durability and cleanliness (Shishoo 2005).

Table 1. Properties of sportswear and shoes incorporated with nanotechnology

\begin{tabular}{|c|c|}
\hline $\begin{array}{c}\text { Main properties of sportswear and shoes } \\
\text { incorporated with nanotechnology }\end{array}$ & Benefits for sports \\
\hline antibacterial & all types of sportswear and shoes \\
\hline comfort & all types of sportswear \\
\hline UV protection & clothing for outdoor sports \\
\hline water-proof & $\begin{array}{c}\text { swimsuit, diving, canoeing, } \\
\text { sport shoes, sailing }\end{array}$ \\
\hline self-cleaning & mountaineering tents \\
\hline protection from cold and heat & $\begin{array}{c}\text { skiing, snowboard, diving, mountaineering, } \\
\text { canoeing and cycling clothes }\end{array}$ \\
\hline electronic textiles & $\begin{array}{c}\text { mountaineering, running and fencing } \\
\text { clothes, referee gadgets }\end{array}$ \\
\hline $\begin{array}{c}\text { enhanced blood circulation \& recovery of } \\
\text { muscles }\end{array}$ & $\begin{array}{c}\text { therapeutic knee bands, elbow bands, } \\
\text { back-belts esp. for weightlifting }\end{array}$ \\
\hline
\end{tabular}

Some case studies are given below. In the production of clothing for racers in cars and motorcycles, the Gore-Tex brand offers a jacket made of waterproof polymer membrane with built-in nanosized carbon particles that resist static charge. NanoTex brand uses nanotechnology to produce Nano-Care stain-resistant clothing. They coat the fibers with a polymer and then woven into fabric, the cloth maintains its stain resistance even after many washes - and the fabric maintains its soft texture and feel. They license the technology to others, including clothing giants The Gap, Nike, and Old Navy. Schoeller Textiles AG (Switzerland) has developed a nanobased technology to produce clothing with optimal balance of comfort, air permeability, wind and water resistance and self-cleaning property for extreme cold 
weather sports such as mountaineering and ski (Montazer et. al. 2016). The topic of smart nanotextiles in sports is quite extensive and can be considered separately.

\section{Application of nanotechnology in some sports areas}

Nanotechnology has also found applications in car racing. NT treating of sports cars reduces friction, resulting in increased engine power and better fuel economy (Booker $\&$ Boysen 2005). Cars will have lighter and stronger engine blocks and frames and will use new additives making fuel more efficient. The development of materials ten times stronger than steel - but a tenth of the weight - offers to make transportation faster and more efficient. The use of solid and light carbon nanoparticles in the production of bicycles reduces their weight and increases their power.

NT makes sports secure and improves the health of both athletes and ours. NT delivers faster intensive medical help. Detecting disease at the molecular level will lead to timely detection of a disease, timely and new treatment for new and old diseases. For example, General Electric is focused on material performance. They are working on nanotubes, nanorods, nanoceramics, nanostructured metal alloys, and self-assembled block polymers. There are endless applications of improved material performance for this electronics giant (including everything for sports and diagnostic imaging scanners).

Nanotechnology in sports medicine (Bayram, Işıklı \& Denkbaş 2014) is general adaptation of all kinds of developments in nanoscale into medicinal applications related with sports injuries. The adapted developments can be either directly related with the medical interventions such as regeneration of a tissue, implantation, and drug therapies or supporting elements like imaging, strapping, and tapings. The progress in textile industry, imagings, tissue engineering, and drug delivery with the help of nanotechnology-based approaches exhibits new products and methods for the medical area, and they increase day by day.

The use of aluminium-based composite nanomaterials in sports facilities and equipment (especially in cars, bicycles and constructions) makes them lighter, stronger and safer. Research and development of such aluminium-based nanocomposites will be greatly assisted by the research that we are developing (at the Department of Space Materials Science, SRTI-BAS) in the field of new nanocomposites based on nanomicrocrystalline aluminium alloys (Petrova, Stefanov \& Miteva 2020) and functionally graded materials (Miteva 2014).

More powerful and smaller computers, created by NT, will encrypt our data and provide round-the-clock security. Chemical sensors based on NT are incredibly sensitive (Booker \& Boysen 2005). Small computers and sensors will make the life and work of athletes safer. The investigations on electric field effects in semiconductor quantum well structures are the basis for searching new structures for electric field effect device with sports applications. This type of research that we do (Miteva, Vlaev \& Donchev 2008) would be useful in developing advanced electro-optical devices for use in sports.

Undoubtedly, nanomaterials can make some of the sports facilities and sports equipment many times better. However, despite the various advantages proposed, 
there is not a myriad of nanotechnology-enhanced sports equipment in the market as the technology is highly expensive and complicated to deal with (Ćibo et.al. 2019). The biggest category of the nanotechnology sports products on the market now is health and fitness, which includes clothing, cosmetics and sunscreens. This category also includes sports equipment that includes improved tennis balls and stronger rackets.

Although nanomaterials in different sports sections have brought many benefits to the sport community, they possibly have negative impact on the environment and organisms, threatening the human health (Zhao \& Shen 2012). Thus, more attention should be paid on the biological study of nanomaterials, developing sports engineering with negligible harmful effect.

\section{Conclusion}

The desire for sport products with enhanced performance and efficiency has been known for many years. The use of nanomaterials in sports engineering has led to the scientific development of sports. Today nanotechnology is widely used in sports and it has revolutionized many aspects of sport engineering including sport venues, sport equipment, floor coverings and clothing, sports medicine and sports security.

Nano-enhanced sports equipment is much more advanced and superior in terms of strength, rigidity and durability compared to conventional sports equipment. Various companies offer more innovative ideas for further application of nanotechnology to improve sports equipment. Many prominent athletes choose nano-built sports equipment to enhance their performance. In connection with the growing role of nanotechnology and the huge amount of research in this area, there is a need to develop new methods and ideas for the production of sports goods using nanotechnology. The sportswear market has grown significantly in recent years and innovative products are constantly being produced, with performance, quality and design as decisive factors. The future approach will focus on meeting the multifunctional requirements for sports products.

Medicine-related nanotechnology materials provide additional added value in all areas as they help patients/athletes regain their health and improve their quality of life.

Nanotechnology products will continue to emerge with new applications; however, scientists, manufacturers and regulatory agencies must ensure that these technologies do not adversely affect human health and the planet during their production and life cycle.

Nanotechnologies, in which we could contribute something new in the field of sports, preferably with the help of minimal financial costs, can be theoretical modeling of new nanostructured materials and devices, such as semiconductor nanostructures (for electrooptic device applications), and aluminium-based nanocomposites and functionally graded materials (for nanostructure sports applications in automotive and construction industries). The work is in progress in this direction. 


\section{REFERENCES}

Bayram, C., Işıklı, C. \& Denkbaş, E. B., 2014. Nanotechnology in Sports Medicine. In: Doral M. \& J. Karlsson (Eds.). Sports Injuries. 1 - 9. Berlin: Springer, https://doi.org/10.1007/978-3-642-36801-1_243-1

Booker, R. D. \& Boysen, E., 2005. Nanotechnology for dummies. Indianapolis: John Wiley \& Sons.

Ćibo, M., Šator, A., Kazlagić, A. \& Omanović-Mikličanin, E., 2019. Application and Impact of Nanotechnology in Sport. In: M. Brka, E. Omanović-Mikličanin, L. Karić, V. Falan \& A. Toroman (Eds.). 30th Scientific-Experts Conference of Agriculture and Food Industry. Cham: Springer, 349 - 362. https://doi.org/10.1007/978-3-030-40049-1

Gong, Z. G., 2013. Nanotechnology application in sports. Advanced materials research. 662, 186 - 189. https://doi.org/10.4028/www. scientific.net/amr.662.186

Harifi, T. \& Montazer, M., 2017. Application of nanotechnology in sports clothing and flooring for enhanced sport activities, performance, efficiency and comfort: a review. Journal of Industrial Textiles. 46(5), 1147 - 1169. https://doi.org/10.1177/1528083715601512

Miteva, A. M., Vlaev, S. J. \& Donchev, V. T., 2008. Stark Effect in p-type Delta-doped Quantum Wells. Progress In Electromagnetics Research Letters, 2, 45 - 52. Available from: doi:10.2528/PIERL07122809

Miteva, A., 2014. An overview of the functionally graded materials. Machines. Technologies. Materials. 8(3), 13 - 16. https://stumejournals. com/journals $/ \mathrm{mtm} / 2014 / 3 / 13$

Petrova, A., Stefanov, G. \& Miteva, A., 2020. Some properties of the nanozone in nano-microcrystalline ribbons of aluminium alloys. Comptes rendus de l'Académie bulgare des Sciences. 73(10), 1434 - 1442. Available from: DOI:10.7546/CRABS.2020.10.13

Shishoo, R., 2005. Textiles in sport. Elsevier. Cambridge: Woodhead Publishing10. Yetisen, A. K., et al., 2016. Nanotechnology in textiles. ACS nano. 10(3), 3042 - 3068. https://doi.org/10.1021/acsnano.5b08176

Zhao, H. E. \& Shen, F., 2012. The applied research of nanophase materials in sports engineering. Advanced Materials Research. 496, 126 - 129. https://doi.org/10.4028/www.scientific.net/AMR.496.126

Adelina Miteva

https://orcid.org/0000-0002-2456-8640; Space Research and Technology Institute Bulgarian Academy of Sciences Sofia, Bulgaria E-mail: ad.miteva@gmail.com 